\section{Original} article

African Medical and Research Foundation (AMREF) Mwanza, Tanzania

H Grosskurth

E Mwijarubi

P Mayaud

B Cleophas

R Mkanje

A Gavyole

London School of Hygiene and Tropical Medicine, London, UK H Grosskurth

J Todd

K Orroth

P Mayaud

R Hayes

D Mabey

Municipal Health Office Mwanza,

Tanzania

M Rwakatare

L Ndeki

Regional Medical Office Mwanza,

Tanzania

A Gavyole

National Institute for Medical Research (NIMR) Mwanza, Tanzania

J Todd

Institute for Tropical Medicine Antwerp,

Belgium

A Buvé

Correspondence to: Dr H Grosskurth, London School of Hygiene and Tropical Medicine, Department of Infectious and Tropical Diseases, Keppel Street, London WC1E 7HT, UK

Heiner.Grosskurth@1shtm.ac.uk

Accepted for publication 12 September 2000

\title{
Operational performance of an STD control programme in Mwanza Region, Tanzania
}

\author{
Heiner Grosskurth, Ezra Mwijarubi, James Todd, Medard Rwakatare, Kate Orroth, \\ Philippe Mayaud, Bernadette Cleophas, Anne Buvé, Rashid Mkanje, Leonard Ndeki, \\ Awene Gavyole, Richard Hayes, David Mabey
}

Objectives: To describe important details of the design and operational features of the Mwanza sexually transmitted diseases (STD) control programme. To assess the feasibility of the intervention, the distribution of STD syndromes observed, the clinical effectiveness of syndromic STD case management, the utilisation of STD services by the population, and the quality of syndromic STD services delivered at rural health units.

Methods: The intervention was integrated into rural primary healthcare (PHC) units. It comprised improved STD case management using the syndromic approach, facilitated by a regional programme office which ensured the training of health workers, a reliable supply of effective drugs, and regular support supervision. Five studies were performed to evaluate operational performance: (i) a survey of register books to collect data on patients presenting with STDs and reproductive tract infections (RTIs) to rural health units with improved STD services, (ii) a survey of register books from health units in communities without improved services, (iii) a survey of register books from referral clinics, (iv) a home based cross sectional study of STD patients who did not return to the intervention health units for follow up, (v) a cross sectional survey of reported STD treatment seeking behaviour in a random cohort of 8845 adults served by rural health units. Results: During the 2 years of the Mwanza trial, 12895 STD syndromes were treated at the 25 intervention health units. The most common syndromes were urethral discharge $(67 \%)$ and genital ulcers (26\%) in men and vaginal discharge (50\%), lower abdominal tenderness (33\%), and genital ulcers $(13 \%)$ in women. Clinical treatment effectiveness was high in patients from whom complete follow up data were available, reaching between $81 \%$ and $98 \%$ after first line treatment and $97 \%-99 \%$ after first, second, and third line treatment. Only $26 \%$ of patients referred to higher levels of health care had presented to their referral institutions. During the trial period, data from the cohort showed that $12.8 \%$ of men and $8.6 \%$ of women in the intervention communities experienced at least one STD syndrome. Based on various approaches, utilisation of the improved health units by symptomatic STD patients in these communities was estimated at between $50 \%$ and $75 \%$. During the first 6 months of intervention attendance at intervention units increased by $53 \%$. Thereafter, the average attendance rate was about $25 \%$ higher than in comparison communities. Home visits to 367 non-returners revealed that $89 \%$ had been free of symptoms after treatment, but $28 \%$ became symptomatic again within 3 months of treatment. $100 \%$ of these patients reported that they had received treatment, but only $74 \%$ had been examined, only $57 \%$ had been given health education, and only $30 \%$ were offered condoms. Patients did not fully recall which treatment they had been given, but possibly only $63 \%$ had been treated exactly according to guidelines.

Conclusions: This study demonstrated that it is feasible to integrate effective STD services into the existing PHC structure of a developing country. Improved services attract more patients, but additional educational efforts are needed to further improve treatment seeking behaviour. Furthermore, clear treatment guidelines, a reliable drug supply system, and regular supervision are critical. All efforts should be made to treat patients on the spot, without delay, as referral to higher levels of care led to a high number of dropouts. The syndromic approach to STD control should be supported by at least one reference clinic and laboratory per country to ensure monitoring of prevalent aetiologies, of the development of bacterial resistance, and of the effectiveness of the syndromic algorithms in use.

(Sex Transm Inf 2000;76:426-436)

Keywords: sexually transmitted infections; syndromic treatment; programme performance; Tanzania

\section{Introduction}

The importance of sexually transmitted diseases (STDs) for the public health of developing countries has increasingly been recognised in recent years. The 1993 World Development Report identified STDs (without HIV infection) as the second most important cause of loss of healthy life years in women of childbearing age. ${ }^{1}$ While STDs present a serious public health problem in their own right, they also play an important part as co-factors in the facilitation of sexually transmitted HIV infection. Evidence for this hypothesis has come from a variety of studies, ${ }^{2-5}$ and at the end of the 1980s it was proposed that the effective control of STDs would lead to a substantial reduction in HIV transmission. ${ }^{6}$ The World Health Organization (WHO) recommends treatment of STDs and other reproductive tract infections (RTIs) using the syndromic approach. ${ }^{7}$ Patients are treated based on their signs and symptoms with a 
combination of drugs covering all the major causative agents that might be responsible for the syndrome observed. This strategy is particularly suitable for peripheral health units in developing countries which do not have any reliable laboratory facilities. The approach also enhances compliance because patients are treated at the place and time of first contact, thus avoiding waiting time and dropouts.

Between 1991 and 1994 a randomised controlled intervention trial was conducted in the Mwanza Region of Tanzania in order to evaluate the feasibility of this strategy and its impact in a cohort of about 12000 adults. ${ }^{8}$ The trial demonstrated that this intervention strategy reduced HIV incidence in the general population by $38 \%$, and led to significant reductions in the prevalence of syphilis and symptomatic male urethritis. ${ }^{910}$ The intervention was shown to be highly cost effective. ${ }^{11}$ The trial results have had a considerable influence on policy for HIV prevention, and programmes to improve STD treatment services at primary healthcare (PHC) level are presently being introduced in many developing countries worldwide. To support these efforts and to aid interpretation of the trial findings, we believe it is important to disseminate information on the methodology of the intervention, to examine its operational performance and its limitations, and to discuss key lessons learned and ways in which the intervention might be improved further.

The objectives of this paper are to describe important details of intervention design and implementation, to assess the pattern of STD syndromes seen in intervention communities, to estimate the clinical effectiveness of syndromic STD case management, and to assess the utilisation and the quality of STD services delivered at rural PHC units.

\section{Methods}

STUDY POPULATION AND HEALTH UNITS

Mwanza Region is situated on the southern shores of Lake Victoria. By the time of the trial, the region comprised six districts including an archipelago in the lake, and had about two million inhabitants. Mwanza town is an urban centre with traffic connections to other regions of Tanzania and to central Africa, Kenya, and Uganda via road, rail, and boat. However, most of the region is rural in character, and has a semi-arid landscape. The population lives mainly on subsistence farming and fishing, cotton and maize being the main cash crops. The Sukuma are the predominant ethnic group.

Twelve large rural communities, with an average population of about 25000 , participated in the trial. ${ }^{8}$ A community was defined as a group of villages forming the catchment area of a rural health centre and three to four satellite dispensaries. In Tanzania, healthcare services at primary level are provided through health centres and dispensaries (both called health units in this paper). A health centre has about $8-12$ trained staff and is managed by a medical assistant (MA). A dispensary has two to three trained staff and is led by a rural medical aide (RMA). Both cadres have a formal training of 3 years, which until the time of the study did not include syndromic STD case management. Before the STD intervention was introduced, the drug supply was restricted to monthly supplies with standardised kits as part of the national essential drug programme (EDP). Frequently, drugs from these kits were out of stock before the end of the month. Furthermore, short acting penicillin and tetracycline were the only antibiotic drugs available in these kits.

The study communities were formed into six matched pairs using geographical characteristics and pretrial STD case attendance as matching criteria, and one community from each pair was randomly allocated to the intervention group. ${ }^{8}$ After the trial was completed, the intervention was extended to the six comparison communities and to other towns and villages in the Lake Victoria zone of Tanzania, and it is now being extended to other regions of the country.

\section{DESIGN OF THE STD INTERVENTION \\ Integration}

The intervention was integrated into the existing primary healthcare structure of the districts, using the available staff and health units. STD services were part of routine outpatient care, thus avoiding special clinic hours for STD patients. Training and, initially, supervision and drug supply were organised centrally through a regional programme office. This office was situated in Mwanza in the premises of the African Medical and Research Foundation (AMREF), a non-governmental organisation charged with the facilitation of the intervention. Later, supervision and drug supply were decentralised and are now the responsibility of the district health teams.

\section{Health workers}

From each of the participating health units, selected staff members were trained in STD case management. These included the officer in charge of the unit and usually one additional MA or RMA who regularly attended outpatients. In some of the more remote dispensaries, treatment, including that of STDs, is provided by nurses or occasionally even auxiliary staff. Although these workers are officially not permitted to prescribe, a pragmatic decision was made not to exclude such workers from STD training. Except during training courses health workers did not receive any remuneration or allowance for their participation in the programme.

\section{Training}

Training courses lasted 1 week. The syllabus covered the syndromic management of STDs, health education, condom demonstration and partner notification, which were practised intensively through role plays. Much importance was given to a non-judgmental attitude of health workers towards STD patients. Teaching was kept as simple and practical as possible and avoided any emphasis on aetiological aspects of STDs. A 3 day 
Table 1 Main STD/RTI syndromes and their causative agents occurring in Mwanza Region, with treatment regimens used for each syndrome in the STD intervention

\begin{tabular}{|c|c|c|}
\hline Syndrome & Common aetiologies in east $A$ frica & Treatment regimen used in the STD intervention \\
\hline Genital ulcer & $\begin{array}{l}\text { - chancroid (Haemophilus ducreyı) } \\
\text { - syphilis (Treponema pallidum) } \\
\text { - herpes (herpes simplex virus-2) }\end{array}$ & $\begin{array}{l}\text { (1) TMP-SMX } 320 \mathrm{mg} / 1600 \mathrm{mg} \text { bd for } 2 \text { days }+ \text { benzathine penicillin } \\
2.4 \text { million units im stat } \\
\text { (2) TMP-SMX } 320 \mathrm{mg} / 1600 \mathrm{mg} \text { bd alternate days } \times 3 \\
\text { (3) Ciprofloxacin } 250 \mathrm{mg} \text { bd for } 3 \text { days (no treatment for herpes) }\end{array}$ \\
\hline Urethral discharge in men & $\begin{array}{l}\text { - gonorrhoea (Neisseria gonorrhoeae) } \\
\text { - chlamydia infection (Chlamydia trachomatis) } \\
\text { - trichomoniasis (Trichomonas vaginalis) }\end{array}$ & $\begin{array}{l}\text { (1) TMP-SMX } 400 \mathrm{mg} / 2000 \mathrm{mg} \text { bd for } 2 \text { days }+ \text { doxycycline } 100 \mathrm{mg} \text { bd } \\
\text { for } 7 \text { days } \\
\text { (2) Metronidazole } 2 \mathrm{~g} \mathrm{stat}+\text { doxycycline } 100 \mathrm{mg} \text { bd for } 7 \text { days } \\
\text { (3) Ciprofloxacin } 500 \mathrm{mg} \mathrm{stat}\end{array}$ \\
\hline Vaginal discharge & $\begin{array}{l}\text { - trichomoniasis } \\
\text { - bacterial vaginosis (anaerobic bacteria) } \\
\text { - cervical infections (gonococcal and chlamydial) } \\
\text { - if appears like thrush: candidiasis (Candida albicans) }\end{array}$ & $\begin{array}{l}\text { (A) If discharge does not appear like thrush: } \\
\text { (1) TMP-SMX } 400 \mathrm{mg} / 2000 \mathrm{mg} \text { bd for } 2 \text { days }+ \text { doxycycline } 100 \mathrm{mg} \text { bd } \\
\text { for } 7 \text { days }+ \text { metronidazole } 2 \mathrm{~g} \text { stat } \\
\text { (2) Doxycycline } 100 \mathrm{mg} \text { bd for } 7 \text { days } \\
\text { (3) Ciprofloxacin } 500 \mathrm{mg} \text { stat } \\
\text { (B) If discharge appears like thrush: } \\
\text { Nystatin pessaries one at night, for } 7 \text { days } \\
\text { or: application of } 1 \% \text { gentian violet solution }\end{array}$ \\
\hline Lower abdominal tenderness & $\begin{array}{l}\text { if caused by pelvic inflammatory disease (PID): } \\
\text { - gonorrhoea } \\
\text { - chlamydia infection } \\
\text { - anaerobic bacteria }\end{array}$ & $\begin{array}{l}\text { (1) TMP-SMX } 400 \mathrm{mg} / 2000 \mathrm{mg} \text { bd for } 2 \text { days }+ \text { doxycycline } 100 \mathrm{mg} \text { bd } \\
\text { for } 14 \text { days }+ \text { metronidazole } 400 \mathrm{mg} \text { bd for } 7 \text { days } \\
\text { (2) Ciprofloxacin } 500 \mathrm{mg} \text { stat }\end{array}$ \\
\hline
\end{tabular}

NB: in pregnancy, doxycycline and ciprofloxacin are replaced by erythromycin ( $500 \mathrm{mg}$ td for 7 days).

(1) Treatment given at first visit.

(2) Treatment given if no improvement after 7 days and reinfection unlikely.

(3) Treatment given if no improvement after further 7 days and re-infection unlikely.

$\mathrm{bd}=$ twice per day, $\mathrm{td}=$ three times per day, stat $=$ single dose, $\mathrm{im}=$ intramuscular, TMP-SMX $=$ trimethoprim-sulfamethoxazole.

refresher training course was held after 18 months.

Two MAs and two senior nurses with experience in syndromic STD case management acted as trainers. The MAs also worked regularly as supervisors of health units, thus providing direct feedback of real life experience into the training. Physicians were not involved in the training, except in the design phase.

A practical training period of 2 weeks followed within 8 weeks of the initial course. For this purpose, trainees joined the STD reference clinic in Mwanza town. They were attached to an experienced clinician, no more than two trainees working in the same room. During these practicals, trainees usually observed the clinician treating at least two cases of each syndrome, and thereafter managed at least two cases of each syndrome themselves under supervision.

A simple self instructional manual on STD case management was available in Kiswahili and English. ${ }^{12}$ The manual was given to health workers a month before their training, and was then used as a textbook during the classroom sessions and the practical training. Each health worker received also a set of syndromic treatment flow charts in transparent covers which they took home for use in their health units.

\section{Syndromic case management}

Based on national guidelines, WHO recommendations, and the microbiological situation in Tanzania, treatment algorithms were developed for each STD syndrome. These were kept as simple as possible, avoiding loops or side branches. Table 1 provides an overview of the main STD syndromes, their causative agents, and the drugs used in the various syndromic treatment algorithms. Case management included a brief history, a clinical examination, health education including condom promotion, and treatment. Sexual partners were notified through the index case by means of a small "contact card" which contained a request to attend the clinic and the register number of the index case. Partners were offered health education and a clinical examination, and treatment according to the syndrome of the index case, regardless of whether or not they had STD symptoms or signs.

Recording and follow up of patients and treatment outcomes

Each health unit kept a separate register book for STD patients. Records included the most essential information only: serial registration number, name, sex, syndromic diagnosis, treatment given, condom uptake, and follow up observation. All STD patients were asked to return at weekly intervals until they were cured. Observations and additional treatments given were recorded at each follow up visit, until a final outcome was reached. Possible outcomes included "cured, treatment failure, loss to follow up, or referred". Register books were regularly checked during supervisory visits.

\section{Supervision and in-service training}

Supervision of STD services at health units was provided by the district STD control coordinator (DSCC). From each of the six districts, one experienced clinician (MA) was trained to fulfil this newly created function. The DSCC worked under the district medical officer (DMO). During the first phase of the trial, while DSCCs were not yet available and the number of participating units was still small, supervision was performed by a regional coordinator (a senior MA), who trained the DSCCs at the same time. Initially each health unit was visited once a month. After health workers had become confident with the syndromic approach, visits were performed at quarterly intervals. The work of supervisors was facilitated by a detailed checklist. During supervisory visits, difficult cases were discussed and training topics reviewed. Patient register books were checked and deviations from the syndro- 
mic algorithms analysed, drug consumption was audited and drugs replenished. Occasionally, DMOs made supervisory visits as well. Other physicians - for example, those who participated in the research component of the trial, were not involved in the intervention.

\section{Health educational campaigns}

At the beginning of the programme, the population was informed that improved STD treatment services were now available at the local health unit. The importance of early treatment for STDs was emphasised. For this purpose, campaigns were conducted on market days using large picture boards to attract the population. District personnel acted as health educators. These campaigns were repeated approximately twice a year.

\section{Logistics}

Rural health units were provided with essential equipment where this was not available. Such equipment comprised an examination bed, bedsheets, a screen, a bench, a stool and a wooden box to store the drugs, all locally produced. A torch (flashlight), a rubber cloth for the bed, and plastic mugs and bowls were also supplied. Occasionally, doors or windows were repaired to ensure privacy for STD patients. Specula for vaginal examinations were initially also provided, but this was discontinued after it became clear that health workers could not acquire the necessary skills during the short training period.

Drugs were ordered and supplied to the districts by the programme office in Mwanza. DSCCs supplied drugs to health units, based on the consumption which was cross checked against the patient register books. The whole process was audited by the programme office. A year after the end of the trial, drug supply was taken over by the newly established STD control component of the national AIDS control programme.

\section{STD reference clinic}

At the municipal hospital in Mwanza town a reference clinic was established and integrated into the outpatient department. The clinic served mainly patients from the town, and had four objectives: to monitor prevalent aetiologies of STD syndromes, to monitor the effectiveness of the syndromic algorithms in use, to monitor antibiotic susceptibility of Neisseria gonorrhoeae, and to train health workers for the intervention in rural health units. It was not routinely used as a referral clinic for peripheral health units.

\section{EVALUATION OF THE INTERVENTION}

Data on the operational performance of the intervention were collected through five studies:

- a survey of register books from health units in intervention communities

- a survey of register books from health units in comparison communities

- a survey of register books from referral clinics
- a community based cross sectional survey of STD patients who did not return for follow up (non-returner study)

- a cross sectional survey of the general population cohort that was followed up for the purpose of the randomised trial (treatment seeking behaviour study).

The studies received approval from the ethics committee of the London School of Hygiene and Tropical Medicine and from the National AIDS Control Programme of Tanzania.

Survey of health unit register books in intervention communities

The Mwanza trial extended from December 1991 to December 1994, 3 years in total because of the phased trial design, but only 2 years for each participating community. At the end of the trial, the STD patient register books were collected from each of the intervention health units. Data were analysed for the duration of the trial - that is, for 24 months. Information on the number of STD syndromes treated, clinical treatment outcomes, the number of partners treated, and on condom uptake was extracted and compiled using a spreadsheet program (Microsoft Excel 5.0).

Survey of health unit register books in comparison communities

In 1994 a survey was conducted of six health centres and 12 randomly selected dispensaries situated in comparison communities of the Mwanza trial. Data were collected before the intervention was extended to these health units. Patient register books were analysed for the year 1993. The number of STD patients registered during this 12 month period was recorded.

Follow up study of referred patients

Some patients were referred from their health unit to a higher level of health care. The reason for referral from dispensaries was mostly a treatment failure after second line treatment, as dispensaries were initially not equipped with the drugs for third line treatment. Health centres referred patients if the health workers were not clear about the diagnosis, if they suspected HIV infection in addition to the STD, and in very rare cases because of treatment failure even after third line treatment.

After completion of the trial a list of all referred cases was compiled, based on the survey of health unit register books. The list comprised the names of the index case, the syndromic diagnosis, and the name of the health institution to which the patient had been referred. Approval for follow up of these cases was obtained from the regional medical officer, and from the medical officers in charge of all potential referral facilities and of all hospitals in the region that referred patients might alternatively have chosen to visit. These facilities were visited and the patient register books carefully searched for the periods during which the referrals had been made. For patients who 
could be traced the investigator recorded the diagnosis, the treatment given at the referral unit, and the outcome.

\section{Non-returner study}

Soon after the end of the trial a study was conducted to investigate clinical cure rates in STD patients who had not returned to the clinic for follow up as requested. From the health centre and from two randomly selected dispensaries in each of the six intervention communities, a list of such patients was compiled. Eligible for this study were patients who had presented for treatment of an STD/RTI at least 2 weeks but no more than 3 months previously, and who had not completed their follow up visits.

All eligible patients were visited at home. To protect the confidentiality of STD patients, a similar number of patients with other recently treated ailments such as cough, diarrhoea, and fever were also contacted. Consenting individuals were interviewed using a structured questionnaire, and an examination was offered. Present symptoms and signs and self reported outcome of the recent STD episode were recorded. Any current STD syndromes were treated on the spot. Data were also collected on patients' experience of the care provided regarding clinical examination, health education, condom promotion, treatment received, and perceived satisfaction with the services.

Treatment seeking behaviour study

As part of the intervention trial, a cohort of about 1000 men and women aged $15-54$ years was recruited from each of the intervention and comparison communities before the intervention was introduced, using random cluster sampling. ${ }^{89}$ Seventy one per cent of the original cohort were successfully followed up after 2 years. On this occasion, after informed consent had been obtained, all study participants were interviewed using a structured questionnaire, and were asked whether they had experienced an episode of genital discharge or genital ulcer during (a) the previous year and (b) the previous 2 years. Study participants who reported such symptoms during the previous 2 years were asked about their treatment seeking behaviour with respect to the most recent episode. Responses included whether treatment had been sought from the official health facility, from a traditional healer or shop, or not at all. Within each matched pair of communities, the relative risk (RR) of seeking treatment from a health facility in the intervention community relative to the comparison

Table 2 Number and pattern of STD/RTI syndromes treated at 25 intervention health units in Mwanza Region

\begin{tabular}{|c|c|c|c|c|}
\hline \multirow[b]{2}{*}{ Syndromes $(N=12$ 895) } & \multicolumn{2}{|l|}{ Men } & \multicolumn{2}{|l|}{ Women } \\
\hline & $N=5959$ & $(46 \%)$ & $N=6936$ & $(54 \%)$ \\
\hline Genital discharge & 3967 & $67 \%$ & 3493 & $50 \%$ \\
\hline Lower abdominal tenderness ${ }^{\star}$ & & & 2298 & $33 \%$ \\
\hline Genital ulcer & 1524 & $26 \%$ & 877 & $13 \%$ \\
\hline Other syndromes† & 468 & $8 \%$ & 268 & $4 \%$ \\
\hline Patients reporting two syndromes & 55 & $1 \%$ & 123 & $2 \%$ \\
\hline
\end{tabular}

*Treated as pelvic inflammatory disease.

+Buboes without ulcer, balanitis, suspected secondary syphilis, genital warts, epididymitis, pubic lice. community was computed for different STDs. A point estimate of the overall $R R$ was calculated as the geometric mean of the pair specific RRs. Statistical significance was assessed with the paired $t$ test on the logarithms of the RRs, and corresponding 95\% confidence intervals (CIs) for the RRs were obtained.

\section{Results}

KEY OBSERVATIONS DURING INTERVENTION

Health units

Six health centres and 20 dispensaries participated in the six intervention communities. During the first year services at one of the dispensaries were discontinued. Data were compiled from the 25 health units which participated throughout the 2 year trial period.

\section{Supervision}

Regular supervision proved to be very important for the success of the intervention. During the initial phase, when the syndromic strategy had just been introduced to a clinic, many health workers found it difficult to put their training into practice without support from their supervisor. Over time, about $20 \%$ of the health workers showed a tendency to deviate from the syndromic treatment guidelines, usually by prescribing incorrect medication, but this was rectified through supervisory visits and in-service training.

STD SYNDROMES DIAGNOSED AT HEALTH UNITS The survey of health unit register books showed that a total of 12895 STD syndromes were diagnosed and treated over 2 years (table 2 ). There were similar numbers of cases in men and women; 178 patients $(1.4 \%)$ presented with more than one syndrome. The most common syndromes in men were urethral discharge $(67 \%)$ and genital ulcers (26\%), and in women were vaginal discharge ( $50 \%)$, lower abdominal tenderness (treated as suspected pelvic inflammatory disease) (33\%), and genital ulcers $(13 \%)$. Other syndromes, including buboes without ulcer, balanitis, suspected secondary syphilis, genital warts, epididymitis, and pubic lice were relatively uncommon.

CLINICAL EFFECTIVENESS OF SYNDROMIC STD CASE MANAGEMENT

Data from the survey of health unit register books During the 2 years of follow up, data on treatment effectiveness were collected for genital ulcer, urethral discharge, and vaginal discharge syndromes from health units in the intervention communities. Outcomes were recorded for syndromes rather than patients. From the 9861 reported discharge and ulcer syndromes treated, entries on follow up observations, condom uptake, and partners treated were available from $8942(91 \%)$. Not all of the patients returned until a final outcome was noted, so that a complete follow up assessment was available for only 2937/8942 (33\%) STD episodes (table 3 ).

In all, 2755 of these syndromes (94\%) were clinically cured after first line treatment (table 3). Some required second or occasionally even third line treatment, with an overall clinical 
Table 3 Clinical treatment effectiveness for genital ulcer and genital discharge syndromes summarised over 2 years

\begin{tabular}{|c|c|c|c|c|c|c|c|c|}
\hline & \multicolumn{4}{|l|}{ Men } & \multicolumn{4}{|c|}{ Women } \\
\hline & \multicolumn{2}{|c|}{$\begin{array}{l}\text { GUS } \\
(n=1489)\end{array}$} & \multicolumn{2}{|c|}{$\begin{array}{l}U D S \\
(n=3662)\end{array}$} & \multicolumn{2}{|c|}{$\begin{array}{l}\text { GUS } \\
(n=745)\end{array}$} & \multicolumn{2}{|c|}{$\begin{array}{l}V D S \\
(n=3046)\end{array}$} \\
\hline & No & $\%$ & No & $\%$ & No & $\%$ & No & $\%$ \\
\hline $\begin{array}{l}\text { Assessment completed }{ }^{\star} \\
\text { Of these: }\end{array}$ & 389 & 26 & 1177 & 32 & 235 & 32 & 1136 & 37 \\
\hline Cured after 1 st line treatment & 324 & 83 & 1153 & 98 & 191 & 81 & 1087 & 96 \\
\hline Cured after 1 st- 3 rd line treatment & 381 & 98 & 1161 & 99 & 233 & 99 & 1104 & 97 \\
\hline Definite treatment failure & 2 & 0.5 & 1 & 0.1 & 0 & - & 0 & - \\
\hline Referred & 6 & 1.5 & 15 & 1.3 & 2 & 0.8 & 32 & 3 \\
\hline
\end{tabular}

GUS = genital ulcer syndrome, UDS = urethral discharge syndrome, VDS = vaginal discharge syndrome.

*Total number of syndromes for which a definite outcome is known. Possible outcomes were: cured, definite treatment failure, referred.

cure rate of $98 \%$. Patients with genital ulcer syndromes were more likely to be given second or third line treatment than patients with genital discharge syndromes. Definite treatment failure was observed in only three $(0.1 \%)$ cases (one case of urethral discharge and two cases of genital ulcers, all in men).

Data from the non-returner study

A total of 567 STD patients were eligible for the study of non-returners, 249 men and 318 women; $367(65 \%)$ of these patients were traced at their homes and agreed to participate, 164 men $(66 \%)$ and 203 women $(64 \%)$. The following reasons for non-participation were recorded: wrong address or name $(45 \%)$, travelling $(28 \%)$, moved to another village $(16 \%)$, village inaccessible because of heavy rains $(11 \%)$, died $(0.5 \%)$, and refused to participate $(0.5 \%)$. These reasons were similar in men and women. Non-participants did not differ significantly from participants with respect to type of syndrome or type of treatment received.

The 367 STD patients had presented with 389 STD syndromes, and had been treated at the intervention health units with first line treatment $(90 \%)$, first and second line treatment $(8 \%)$, or first, second, and third line treatment $(2 \%)$. After treatment, no improvement was observed for 42/389 syndromes $(11 \%), 240(62 \%)$ of the syndromes were clinically cured, and for a further $107(28 \%)$ symptoms had disappeared for some time, but had recurred by the time of the survey. In this latter group, it was not possible to distinguish between those who had been cured and reinfected, and those who had not been cured

Table 4 Treatment effectiveness for genital ulcer syndrome and genital discharge syndrome based on a survey of STD/RTI patients who did not return for follow up ${ }^{\star}$

\begin{tabular}{|c|c|c|c|c|c|c|c|c|}
\hline & \multicolumn{4}{|c|}{ Men } & \multicolumn{4}{|c|}{ Women } \\
\hline & \multicolumn{2}{|c|}{ GUS } & \multicolumn{2}{|c|}{$U D S$} & \multicolumn{2}{|c|}{ GUS } & \multicolumn{2}{|c|}{$V D S$} \\
\hline $\begin{array}{l}\text { Number of study participants } \\
\text { Treatment outcome reported by patients: }\end{array}$ & 64 & & 89 & & 42 & & 97 & \\
\hline $\begin{array}{l}\text { No symptoms (=cured and no recurrence) } \\
\text { Symptoms reported: }\end{array}$ & 52 & $81 \%$ & 62 & $69 \%$ & 22 & $52 \%$ & 51 & $53 \%$ \\
\hline Re-infection or recurrence of symptoms & 9 & $14 \%$ & 20 & $23 \%$ & 11 & $26 \%$ & 34 & $35 \%$ \\
\hline Not cured & 3 & $5 \%$ & 7 & $8 \%$ & 9 & $21 \%$ & 12 & $12 \%$ \\
\hline Signs observed by clinician on examination $\dagger$ & 12 & $19 \%$ & 22 & $25 \%$ & 21 & $50 \%$ & 52 & $54 \%$ \\
\hline
\end{tabular}

GUS = genital ulcer syndrome, UDS = urethral discharge syndrome, VDS = vaginal discharge syndrome.

*Information obtained through home visits of patients 2 weeks to 3 months after treatment.

tOne woman with GUS and six women with VDS had signs on examination although they reported that they were free of symptoms. but had become temporarily asymptomatic (recurrence of symptoms).

To facilitate comparison with the clinical outcomes for the main syndromes reported above for patients with complete follow up (table 3), a breakdown of these findings by sex and main syndrome is given in table 4 . The overall treatment failure rate for GUS and GDS was $11 \%$. The reported rate of reinfection or recurrence of symptoms was very high, particularly in women, and this was confirmed on clinical examination.

Combining the information from both studies, it can be estimated that overall the clinical cure rate following syndromic case management amounted to $90-95 \%$.

\section{EFFECTIVENESS OF THE REFERRAL SYSTEM}

During the 2 years of the trial, 97 STD patients (55 patients with GDS/GUS) had been referred, most of them from dispensaries to health centres, and some from dispensaries or health centres to hospitals including the STD reference clinic in Mwanza town.

Only 25 patients $(26 \%)$ reported to the health unit to which they had been referred. The others could not be traced, even at alternative facilities. A complete assessment was only possible in five patients, who were cured; the remainder were lost to follow up after one visit.

\section{UTILISATION OF SERVICES}

Attendance of STD patients in comparison communities

During the survey of register books of units in comparison communities, six health centres and 12 dispensaries were visited. Register books were available for six health centres and 11 dispensaries. In these 17 units 3910 STD patients were recorded for 1993, with about twice as many patients recorded at each health centre than at each dispensary. Extrapolating these figures to six health centres and 19 dispensaries, as in the intervention communities, a total of 5225 STD patients would have been expected in 1993, an average of 435 per month. The average number of STD syndromes would have been slightly higher, as some patients may have had more than one syndrome.

\section{Attendance of STD patients in intervention communities}

According to the survey of patient register books in intervention communities, a total of 402 STD episodes were recorded at the 25 clinics in the intervention communities during the first month of the intervention. The monthly attendance rate then increased steadily to 616 syndromes treated by month 6 , equivalent to an increase of $53 \%$ (fig 1). Thereafter the monthly attendance rate oscillated between 464 and 627 , with an average of $9762 / 18=542$. This is about $25 \%$ above the expected attendance rate based on data from the comparison communities. There was no clear seasonal pattern in the monthly variation in attendance. 
Table 5 Treatment seeking behaviour in intervention and comparison communities in patients reporting genital ulcers and genital discharge syndromes during the past 2 years *

\begin{tabular}{|c|c|c|c|c|c|}
\hline & $\begin{array}{l}\text { Intervention No } \\
(\%)\end{array}$ & $\begin{array}{l}\text { Comparison No } \\
(\%)\end{array}$ & $R R t$ & $(95 \% C I)$ & $p$ Value \\
\hline \multicolumn{6}{|l|}{ Discharge: } \\
\hline \multicolumn{6}{|l|}{ Women } \\
\hline Health facility & $81(50)$ & $95(43)$ & 1.21 & $0.68-2.15$ & 0.429 \\
\hline Other & $38(24)$ & $65(29)$ & & & \\
\hline No treatment & $41(26)$ & $61(28)$ & & & \\
\hline Total & 160 & 221 & & & \\
\hline \multicolumn{6}{|l|}{ Men } \\
\hline Health facility & $102(48)$ & $107(36)$ & 1.79 & $0.71-4.51$ & 0.154 \\
\hline Other & $82(39)$ & $128(43)$ & & & \\
\hline No treatment & $28(13)$ & $61(21)$ & & & \\
\hline Total & 212 & 296 & & & \\
\hline \multicolumn{6}{|l|}{ Both sexes } \\
\hline Health facility & $183(49)$ & $202(39)$ & 1.37 & $0.86-2.18$ & 0.152 \\
\hline Other & $120(32)$ & $193(37)$ & & & \\
\hline No treatment & 69 (19) & $122(24)$ & & & \\
\hline Total & 372 & 517 & & & \\
\hline \multicolumn{6}{|l|}{ Ulcer: } \\
\hline \multicolumn{6}{|l|}{ Women $\ddagger$} \\
\hline Health facility & $23(59)$ & $11(31)$ & 1.99 & $1.35-2.95$ & 0.007 \\
\hline Other & $11(28)$ & $13(37)$ & & & \\
\hline No treatment & $5(13)$ & $11(31)$ & & & \\
\hline Total & 39 & 35 & & & \\
\hline \multicolumn{6}{|l|}{ Men } \\
\hline Health facility & $43(56)$ & $35(44)$ & 1.25 & $0.72-2.17$ & 0.284 \\
\hline Other & $18(23)$ & $33(42)$ & & & \\
\hline No treatment & $16(21)$ & $11(14)$ & & & \\
\hline Total & 77 & 79 & & & \\
\hline \multicolumn{6}{|l|}{ Both sexes } \\
\hline Health facility & $66(57)$ & $46(40)$ & 1.43 & $1.01-2.02$ & 0.043 \\
\hline Other & $29(25)$ & $46(40)$ & & & \\
\hline No treatment & $21(18)$ & $22(20)$ & & & \\
\hline Total & 116 & 114 & & & \\
\hline \multicolumn{6}{|l|}{ Any symptom: } \\
\hline \multicolumn{6}{|l|}{ Women } \\
\hline Health facility & $98(51)$ & $100(41)$ & 1.27 & $0.78-2.05$ & 0.250 \\
\hline Other & $48(25)$ & $76(31)$ & & & \\
\hline No treatment & $45(24)$ & $66(27)$ & & & \\
\hline Total & 191 & 242 & & & \\
\hline \multicolumn{6}{|l|}{ Men } \\
\hline Health facility & $132(51)$ & $129(37)$ & 1.61 & $0.79-3.31$ & 0.120 \\
\hline Other & $92(35)$ & $150(44)$ & & & \\
\hline No treatment & $37(14)$ & $64(19)$ & & & \\
\hline Total & 261 & 343 & & & \\
\hline \multicolumn{6}{|l|}{ Both sexes } \\
\hline Health facility & $230(51)$ & 229 (39) & 1.39 & $0.93-2.09$ & 0.088 \\
\hline Other & $140(31)$ & $226(39)$ & & & \\
\hline No treatment & $82(18)$ & $130(22)$ & & & \\
\hline Total & 452 & 585 & & & \\
\hline
\end{tabular}

${ }^{\star}$ For patients with discharge (and any symptom), data missing for one woman and two men in intervention communities, and for one woman in comparison communities.

tRelative risks (RR) adjusted for cluster design.

$\ddagger$ The RR for the treatment seeking behaviour of women with ulcers could only be calculated for five community pairs rather than six, because of small numbers in one pair.

Proportion of STD cases treated in health units The proportion of STD patients in the community who made use of the improved STD services was estimated using two different

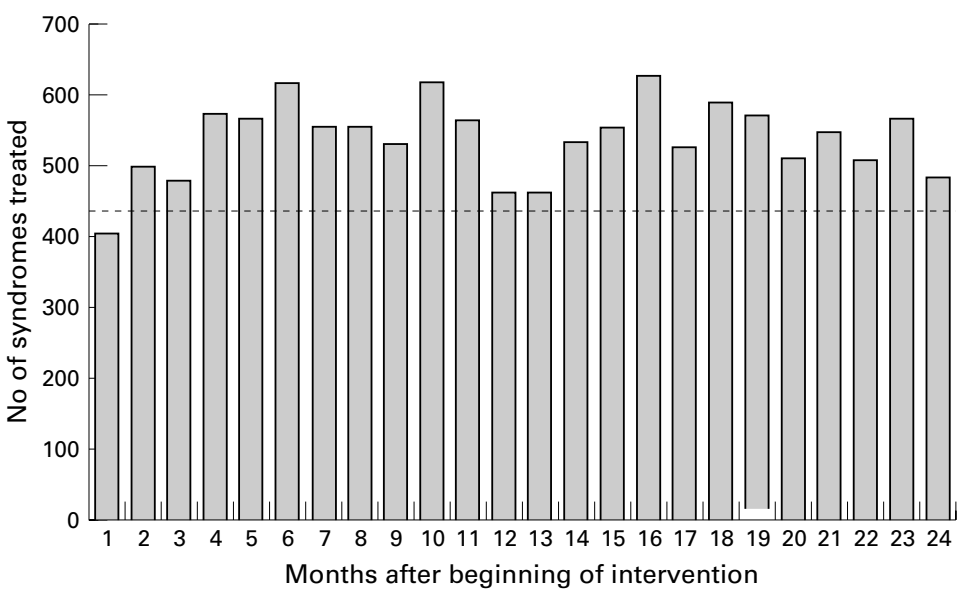

Figure 1 Number of syndromes treated over time in intervention communities (broken line $=$ estimated monthly average of patients treated in comparison communities). methods: (i) from the treatment seeking behaviour study, and (ii) by comparison of the number of STD syndromes treated during the 2 year trial period with the number of STD episodes expected to occur within the catchment of the intervention health units during the same time.

Treatment seeking behaviour study: 12537 adults aged $15-54$ years were enrolled in the study cohort during the baseline survey, representing $85 \%$ of eligible individuals in the selected clusters. After 2 years, 8845 (71\%) cohort members were successfully followed up. Losses to follow up were mostly due to temporary absence from study communities. Participation was similar in men and women and in intervention and comparison communities. In intervention communities, $8.7 \%$ of study participants reported at least one episode of genital discharge, and $2.7 \%$ reported ulcers during the 2 year follow up period. In comparison communities, these proportions were $11.4 \%$ and $2.5 \%$ respectively. Participants reporting symptoms during the past 2 years were asked about their treatment seeking behaviour for the most recent episode. The results are shown in table 5 . Fifty one per cent of participants reporting STD syndromes in intervention communities and $39 \%$ of those in comparison communities, reported that they sought treatment from a local health unit or from a hospital. The proportion seeking treatment from these health units was consistently higher in the intervention than the comparison communities, for both discharge and ulcers in both men and women. For both sexes combined, the difference was significant for ulcers and close to significance for ulcers and discharge combined $(\mathrm{RR}=1.39,95 \%$ CI $0.93-$ $2.09, \mathrm{p}=0.09)$.

Comparison of STD episodes treated with those expected: During the 2 years of the trial, 9861 ulcer and discharge syndromes were treated at the intervention health units (table 2). Based on the data from the trial cohort, the numbers of study participants reporting at least one episode of genital discharge or genital ulcer during the previous year are given in table 6 . The minimum self reported annual incidences of these syndromes were $7.0 \%$ and $2.1 \%$. Fewer women than men reported symptoms. A population of about 150000 lived in the six intervention communities, about 75000 of whom can be assumed to be sexually active people aged 15 and above. This would imply a

Table 6 Self reported STD/RTI symptoms during the past year in a cohort of 8845 men and women in study communities

\begin{tabular}{|c|c|c|}
\hline & Intervention (\%) & Comparison (\%) \\
\hline \multicolumn{3}{|l|}{ Total population } \\
\hline Discharge & $302 / 4286 \quad(7.0)$ & $374 / 4559 \quad(8.2)$ \\
\hline Ulcers & $89 / 4286 \quad(2.1)$ & $79 / 4559 \quad(1.7)$ \\
\hline Any symptoms & $369 / 4286 \quad(8.6)$ & $429 / 4559 \quad(9.4)$ \\
\hline \multicolumn{3}{|l|}{ Women } \\
\hline Discharge & $122 / 2234$ & $147 / 2372 \quad(6.2)$ \\
\hline Ulcers & $29 / 2234 \quad(1.3)$ & $20 / 2372$ \\
\hline Any symptoms & $147 / 2234 \quad(6.6)$ & $162 / 2372 \quad(6.8)$ \\
\hline \multicolumn{3}{|l|}{ Men } \\
\hline Discharge & $180 / 2052 \quad(8.8)$ & $227 / 2187(10.4)$ \\
\hline Ulcers & $60 / 2052$ & $59 / 2187$ \\
\hline Any symptoms & $222 / 2052(10.8)$ & $267 / 2187(12.2)$ \\
\hline
\end{tabular}


minimum of 6825 episodes during 1 year, or 13650 during 2 years. However, this estimate fails to allow for patients experiencing multiple episodes. Assuming only one episode per patient, the proportion seen at clinics would be $72 \%$ (9861/13 650). Assuming 1.2 episodes per patient, the number of episodes expected would be 16380 , and the proportion seen $60 \%$ (9861/16 380). Assuming 1.4 episodes, the proportion seen would be $52 \%$.

\section{Efficiency of partner notification}

In all, 3037 partner treatments were recorded for the 8942 genital ulcer and genital discharge syndromes in intervention communities, equivalent to 34 per 100 index cases. The treatment of two partners was recorded for only $0.5 \%$ of the patients. Treatment of more than two partners was never observed.

\section{Acceptance of condoms}

Health unit staff were trained to routinely promote and offer condoms to STD patients. However, according to the register books, only 83 of $8942(0.9 \%)$ patients with genital ulcer or discharge syndromes accepted condoms. In the non-returner study, only $45 \%$ of male and $19 \%$ of female patients reported that condoms had actually been offered to them (table 7).

PERFORMANCE OF HEALTH WORKERS ACCORDING TO PATIENTS' REPORTS

In the non-returner study, study participants were interviewed regarding various steps in the provider-patient interaction. The results are shown in table 7 . There were no significant differences between the results for different syndromes (data not shown).

Although the need for clinical examination, health education, condom promotion, and correct syndromic treatment had been emphasised during training and supervision, most of these components showed results below expectation. The low rate of reported condom promotion among women is of particular concern. Information on the type and number of drugs received is probably not reliable, but also gives cause for concern.

Thirty three patients $(9 \%)$ reported that they were asked to pay for the services, although services at primary care level in Tanzania were officially free of charge. All of them paid. The sums involved ranged from the equivalents of US $\$ 0.40$ to $\$ 6.80$ per patient.

The proportion of patients in the different communities reporting that they were satisfied

Table 7 Performance of health workers *

\begin{tabular}{lrrrrrr}
\hline & \multicolumn{2}{c}{ Men $(n=164)$} & \multirow{2}{*}{ Women } & \multirow{2}{*}{$(n=203)$} & \multicolumn{2}{c}{ Total $(n=367)$} \\
\hline Patient was examined & 114 & $70 \%$ & 158 & $78 \%$ & 272 & $74 \%$ \\
Patient received health education & 98 & $60 \%$ & 110 & $54 \%$ & 208 & $57 \%$ \\
Condoms were offered & 73 & $45 \%$ & 38 & $19 \%$ & 111 & $30 \%$ \\
Patients received treatment & 164 & $100 \%$ & 203 & $100 \%$ & 367 & $100 \%$ \\
Patient received correct treatment & 114 & $70 \%$ & 117 & $58 \%$ & 231 & $63 \%$ \\
Patient reported full compliance & 157 & $96 \%$ & 183 & $90 \%$ & 340 & $93 \%$ \\
Patient was satisfied with service & 141 & $86 \%$ & 164 & $81 \%$ & 305 & $83 \%$
\end{tabular}

*Information obtained through home visits of non-returners 2 weeks to 3 months after treatment. †The category "patient received correct treatment" was assumed if on demonstration of the various drugs available in the programme, the patient pointed at the correct type of $\operatorname{drug}(\mathrm{s})$ and recalled the correct dose, or if he/she pointed at the correct type of drug(s) but was not sure about how many tablets he/she should have taken. with the services at the health unit ranged from 81 to $86 \%$. Data for men and women were similar.

\section{Discussion}

Feasibility of the intervention

We have shown that a programme to improve the case management of STD syndromes and the treatment seeking behaviour of STD patients substantially reduced HIV transmission and the prevalence of certain STDs, and that this programme was highly cost effective. ${ }^{911}$ But would the programme be feasible and effective outside the conditions of a controlled trial?

The STD services were integrated into the existing primary healthcare units, without additional requirements regarding personnel and physical structure. At the district headquarters, one medical assistant was trained for the post of the DSCC. Thus, the additional burden for the district health system was minimal.

The centrally organised components such as training and drug supply were more demanding. Even so, the personnel routinely involved in these components as well as in the supervision of peripheral health units comprised medical assistants and nurses only. Training courses were short and unsophisticated. It would be possible to reduce costs further by holding training courses at district level, once a sufficient number of experienced medical assistants is available. Alternatively, experienced trainers from a central team could organise courses at the periphery. However, a practical clinical training component is needed. It seems important that trainers have practical experience as supervisors, so that problems observed in the field can be directly fed into the training.

The drugs in use were inexpensive, and the drug supply was coordinated with supervision visits. The single most expensive component in the recurrent costs was the regular supervision system, as this required transport including fuel and maintenance and outstation allowances for supervisors. ${ }^{11}$ Yet regular supervision and in-service training proved to be of paramount importance for the success of the intervention, as health workers tended to deviate from the treatment algorithms or to forget about important components such as health education and partner notification. Supervision was also important to ensure accountability for drugs.

Economic analysis of the intervention has shown that the improvement of STD services cost $\$ 0.39$ per capita annually, or $\$ 10.15$ per syndrome treated of which only $\$ 2.11$ were drug costs. ${ }^{11}$ Both types of costs can be reduced drastically by upscaling the intervention. Indeed, the intervention has been extended to 190 health units within 2 years after the trial, without requiring additional capital investment or additional personnel at central level. On the other hand, it is likely that upscaling may lead to some reduction in the quality of services, particularly if the resources for supervision and in-service training are not equally upscaled as 
well. One thorough supervisory visit every 3 months should be regarded as the absolute minimum.

Utilisation of services

In all, 12895 syndromes were treated during the period of the trial. In previous publications we reported that 11632 syndromes had been treated. ${ }^{9}$ The reason for this discrepancy is that for the previous analysis, data were collated by hand and reported by individual health units. For the purpose of the current report, a careful re-analysis of health unit records was done using computerised spread sheets, and the results were cross checked using records made during supervision visits.

Using two different techniques, we estimated that between $50 \%$ and $75 \%$ of symptomatic STD patients in the area made use of the improved services. Both methods used to make these estimates are subject to error. The results of the treatment seeking behaviour study were possibly affected by (i) recall and reporting bias regarding treatment seeking behaviour, and (ii) by the fact that patients were asked about their most recent episodes while their treatment seeking behaviour may have been different for earlier episodes. The comparison of treated versus expected STD episodes was possibly affected by (i) recall and reporting bias regarding the occurrence and timing of episodes, (ii) uncertainties regarding the size of the catchment population, and (iii) uncertainties regarding the average number of multiple episodes per patient. The net effect of these possible errors on the utilisation rate is difficult to assess.

The substantial increase in attendance observed at the beginning of the trial, and in comparison with comparison communities, was encouraging, demonstrating that an improvement of services can attract more patients. This study also showed that changes in attendance of STD patients do not necessarily reflect changes in disease incidence, as is sometimes erroneously assumed. A decrease in patient numbers may well occur because of a decrease in service quality rather than to a genuine reduction of STDs, and vice versa.

According to the treatment seeking behaviour study, even in communities with improved services $18 \%$ of patients with genital ulcers and $19 \%$ of patients with genital discharge did not seek treatment at all, and there was evidence that many patients made use of alternative treatment outlets. Pharmacies did not exist in these rural study communities, but traditional healers are frequently consulted, ${ }^{13}$ either instead of or in addition to the formal services. Furthermore, anecdotal evidence suggests that some patients in Mwanza delayed treatment seeking for several weeks or months. Similar observations are available from a district in Uganda, ${ }^{14}$ where STD patients reported delays of up to 6 months before seeking treatment. It is important that the improvement of services is accompanied by health educational messages to the community to encourage appropriate treatment seeking behaviour.
Surprisingly, men and women utilised services almost equally. However, fewer women than men presented with genital ulcers or with genital discharge. This is consistent with other studies in Mwanza Region which showed a similar pattern of self reporting ${ }^{15} 16$ and revealed that many infections in women remain genuinely asymptomatic or go unnoticed. In areas with high prevalences of reproductive tract infections, women often perceive milder symptoms as "normal." 14 Again, this demonstrates the need for educational campaigns in such areas.

\section{Clinical treatment effectiveness}

In general, clinical cure rates were very high, and did not deteriorate during the 2 years of the trial (data not shown). Cases of definite treatment failure were very rare. This may change in future, particularly for genital ulcers, as more HIV positive patients reach higher degrees of immunodeficiency. Patients with progressive HIV disease and incurable ulcers due to chancroid and herpes have already been observed at the STD reference clinic in Mwanza town.

Cure rates after first line treatment of ulcers may have been underestimated because ulcers did not always heal within 1 week, and health workers may have erroneously used second line treatment even in cases where some improvement was seen, recording these cases as first line treatment failures. On the other hand, cure rates in patients with genital ulcer may have been overestimated because ulcers due to herpes simplex virus 2 infection are not treatable with the antimicrobial drugs in use, but will normally heal spontaneously. Similarly, syphilitic ulcers will heal spontaneously, even if not correctly treated.

Health workers were trained to treat women with lower abdominal tenderness as cases of pelvic inflammatory disease (PID), provided that there was no reason to suspect a surgical condition. It is likely that some of the patients with this syndrome had other conditions-for example, recurrent pain due to peritoneal adhesions as a result of previous PID episodes. Syndromic STD case management would lead to overtreatment in such cases. On the other hand, the fact that patients usually reported relief from symptoms after treatment argues for an acute inflammatory origin. Studies involving more sophisticated diagnostic techniques such as ultrasound, laparoscopy, and bacterial cultures from the abdominal cavity would be needed to establish what proportion of cases with this syndrome are genuinely associated with PID.

A similar dilemma is presented by the vaginal discharge syndrome. Vaginal symptoms are poor predictors for the dangerous but often asymptomatic cervical infections due to Neisseria gonorrhoeae and Chlamydia trachomatis. If treatment of cervical infections is routinely included in the syndromic management of vaginal discharge (as in our programme), many women will be treated unnecessarily. On the other hand, if the treatment decision is based on a risk assessment step, as recommended by 
the WHO, ${ }^{7}$ many women will remain untreated for cervical infections and others will still be treated unnecessarily for this condition, as both the sensitivity and specificity of this method are low. ${ }^{16}$ Simple and cheap diagnostic tests are urgently needed to solve this diagnostic problem, and could lead to a major improvement in the quality of STD care in the health units of developing countries.

The proportion of patients with complete follow up data was only about $33 \%$. Such patients may not be representative of all patients: cure rates may have been overestimated or underestimated, if a disproportionate number of those patients who failed to improve either stayed away because of disappointment or came forward to request additional treatment.

The non-returner study was an attempt to answer this question. Clinical cure rates in non-returners $(89 \%)$ were somewhat lower than those in patients who returned for complete follow up $(94 \%$ after first line treatment, and $98 \%$ overall), but the difference was not substantial, thus confirming that the algorithms in use were appropriate. Unfortunately, most of the patients in the non-returner study who reported no improvement, had not sought second line treatment. Health workers need to double their efforts in encouraging patients to come for follow up visits, particularly if their symptoms fail to improve.

Because many STDs become asymptomatic after some time even in the absence of effective treatment, it cannot necessarily be assumed that the disappearance of symptoms indicates cure. Microbiological tests of cure were not possible in these rural health units. However, some data were available from the reference clinic in Mwanza town where the same syndromic algorithms were used, and where treatment outcomes were monitored by antimicrobial resistance testing and microbiological tests of cure. During the period of the trial, only $4 \%$ of Neisseria gonorrhoeae strains were fully resistant to trimethoprim-sulfamethoxazole (the first line treatment in our intervention) and none to ciprofloxacin. ${ }^{17}$ Ninety nine per cent of patients with Neisseria gonorrhoeae, Chlamydia trachomatis, Trichomonas vaginalis or Candida albicans infections were clinically cured and pathogens could not be demonstrated after treatment (P Mayaud, unpublished data).

\section{Partner notification rate}

Only for about $35 \%$ of STD patients was a partner notified and treated. Low partner treatment rates have been reported from various STD control projects in developing countries ${ }^{18}$ and are also a well known phenomenon in industrialised countries. ${ }^{19}$ The reasons may include embarrassment, fear of violence and matrimonial conflict, the casual nature of the sexual relationship, and the failure of health workers to adequately explain the importance of partner treatment. Low partner treatment rates are likely to lead to a high risk of reinfection. It is therefore not surprising that in the non-returner study more than a quarter of patients reported that they became symp- tomatic again some time after the initial treatment.

Referrals

Very few cases $(0.8 \%$ of all syndromes treated) needed referral, indicating that peripheral health units were well able to manage STDs. However, of those who were referred only a minority could be traced at the referral centre or at possible alternative sites, such as district or mission hospitals. Some patients may have been missed, but many may have genuinely failed to seek professional care. This is of concern, as such patients may often carry resistant strains. Those who did not report, probably as a result of the high opportunity costs related to time and transport, fell out of the healthcare chain, and were likely to spread the infection further in the community. At the time of the study, there were no skilled private treatment providers in these rural communities, but patients may have sought help from traditional healers. Because of this experience, a decision was taken to include dispensaries in the supply of third line treatment medicines after the end of the trial. STD patients should be treated at the place and time of first contact, and drugs for all lines of treatment should be made available at all levels of care. The referral of STD patients should be avoided whenever possible.

\section{Acceptance of condoms}

Less than $1 \%$ of all STD patients accepted the condoms provided by health workers. This may be an underestimate, as health workers may occasionally have forgotten to record condom uptake. However, there is no doubt that condom acceptance was low. Only about a third of the patients interviewed in the non-returner study reported that condoms were offered to them. This may explain in part the low uptake, although it is also possible that health workers became tired of offering condoms as these were rarely accepted. The reasons for the low acceptance are not well understood, but it is likely that in this traditional rural society condoms carry a negative image. During the same period, AMREF was involved in condom promotion programmes in Mwanza municipality and other towns of the region, and recorded a steadily increasing demand for condoms at hotels, bars, and other outlets. It is possible that in the longer term a similar increase in condom uptake will also be observed in rural areas.

\section{Performance of health workers}

During the training of health workers, great emphasis was placed on correct case management, the necessity for health education regarding risk reduction and treatment compliance, and condom promotion. In spite of this, when non-returners were followed up and interviewed about their experience, it became clear that all these factors showed results below expectation. Only $74 \%$ of the patients reported that they had been examined, only $57 \%$ received health education, and only $30 \%$ were offered condoms (table 6). In women, the latter proportion was as low as $19 \%$. Although it is 
difficult to assess this through an interview conducted weeks or months after treatment, and while all patients reported that they were treated, it is possible that as few as $63 \%$ were treated exactly according to the syndromic algorithms.

These observations are consistent with results from other areas. For example, in a study from Hlabisa in rural South Africa, ${ }^{20}$ only $9 \%$ of patients were correctly managed, recommended drug regimens were prescribed in only $41 \%$, and health education was provided in only $48 \%$. The reasons for these failures are not fully understood, but may be multifactorial: there may be waning of the effect of training, but lack of time and motivation of health workers (who are often underpaid and live in difficult economic circumstances) may also play a part. The importance of good quality supervision cannot be overemphasised.

\section{Conclusions}

This study demonstrated that it is feasible to integrate STD services into the existing PHC structure of a developing country through a practicable and sustainable intervention. It has been shown earlier that the intervention had a significant impact on STD prevalences and on HIV incidence in the community, and that it was highly cost effective. Improved services can attract more patients, but additional educational efforts are needed to improve treatment seeking behaviour. Furthermore, clear treatment guidelines, a reliable drug supply system, and regular supervision are essential. Referral of patients is associated with a high proportion of dropouts, and should be avoided as far as possible. The syndromic management of STDs needs to be supported by at least one reference clinic and laboratory in each country to monitor the prevalent aetiologies, the development of bacterial resistance, and the effectiveness of the syndromic algorithms in use. In view of their role in HIV prevention, it is an urgent priority to implement effective STD control measures in all countries with high STD prevalence and imminent or established HIV epidemics, and donor agencies and governments worldwide must strengthen their commitment to this policy.

We thank the principal secretary, Ministry of Health of the Government of Tanzania and the manager of the National AIDS Control Programme for permission to conduct the studies. We acknowledge the support of the director of the National Institute of Medical Research, Tanzania, and of the administraInstitute of Medical Research, Tanzania, and of the administrative and political authorities at regional, district, ward, and community levels. We are particularly grateful to the health
workers of the rural health units and to the people of Mwanza workers of the rural health units and to the people of Mwanza
Region for their participation and support. We acknowledge the Region for their participation and support. We acknowledge the valuable contributions of Dr Frank Mosha, Dr Kokugonza
Mugeye, and Mr Potence Muhaya during the data collection Mugeye, and Mr Potence Muhaya during the data collection phase, and we thank Dr David Ross for helpful comments on an earlier version of the paper. The studies were funded by the
Commission of the European Communities, with cofunding by Commission of the European Communities, with cofunding by the Centre for International Migration and Development (CIM) of the Federal Republic of Germany, and AMREF Austria.

Conflict of interest: none.

Contributions: This set of five studies was planned and supervised by $\mathrm{HG}, \mathrm{AG}, \mathrm{PM}, \mathrm{JT}, \mathrm{DM}$, and $\mathrm{AB}$. EM and $\mathrm{MR}$ implemented and analysed the survey of health units in communities with improved STD services, and RM and AB that in communities without improved services. The non-returner study was implemented and analysed by BC and LN. KO analysed the treatment seeking behaviour data. Overall data analysis was performed by HG, JT, and RH. The manuscript was prepared by HG, RH, and DM with contributions from all other authors.

1 World Bank. World Development Report 1993. Investing in health. New York: Oxford University Press, 1993.

2 Cameron DW, Simonsen JN, D'Costa LJ, et al. Female to male transmission of human immunodeficiency virus type 1: risk factors for seroconversion in men. Lancet 1989;334: 403-7.

3 Laga M, Manoka A, Kivuvu M, et al. Non-ulcerative sexually transmitted diseases as risk factors for HIV-1 transmission in women: results from a cohort study. AIDS 1993;7:95-102

4 Cohen MS, Hoffman IF, Royce RA, et al. Reduction of concentration of HIV-1 in semen after treatment of urethritis: implications for prevention of sexual transmission of HIV-1. Lancet 1997;349:1868-73.

5 Fleming D, Wasserheit J. From epidemiological synergy to public health policy and practice: the contribution of other public health policy and practice: the contribution of other sexually transmitted diseases to sexual tran
infection. Sex Transm Inf 1999;75:3-17

6 Pepin J, Plummer FA, Brunham RC. The interaction of HIV infection and other sexually transmitted diseases: an opportunity for intervention. AIDS 1989;3:3-9.

7 WHO/GPA. Management of sexually transmitted diseases. WHO/GPA/TEM/94.1, Geneva: World Health Organization, 1994.

8 Hayes R, Mosha F, Nicoll A, et al. A community trial of the impact of improved STD treatment on the HIV epidemic in rural Tanzania: 1. Design. AIDS 1995;9:916-26.

9 Grosskurth H, Mosha F, Todd J, et al. Impact of improved treatment of sexually transmitted diseases on HIV Infection in rural Tanzania: randomised controlled trial. Lancet 1995;346:530-6.

10 Mayaud P, Mosha F, Todd J, et al. Improved treatment services significantly reduce the prevalence of sexually transmitted diseases in rural Tanzania: results of a randomised controlled trial. AIDS 1997;11:1873-80.

11 Gilson L, Mkanje R, Grosskurth H, et al. Cost-effectiveness of improved treatment services for sexually transmitted diseases in preventing HIV-1 infection in Mwanza Region, Tanzania. Lancet 1997;350:1805-9.

12 Nduba J, Mabey D. Self-instructional manual on sexually transmitted diseases (English and Kiswahili editions). Nairobi: African Medical and Research Foundation, 1992.

13 Newell J, Senkoro K, Mosha F, et al. A population-based study of syphilis and sexually transmitted disease syndromes in north-western Tanzania. 2. Risk factors and health seeking behaviour. Genitourin Med 1993;69:421-6.

14 Mulder D. Disease perception and health-seeking behaviour for sexually transmitted diseases. In: Prevention and management of sexually transmitted diseases in Eastern and Southern Africa: current approaches and future directions.
Nairobi: Naresa Monograph No 3, Naresa, PO 11771, 1994.

15 Mosha F, Nicoll A, Barongo L, et al. A population-based study of syphilis and sexually transmitted disease syndromes in north-western Tanzania. 1. Prevalence and incidence; Genitourin Med 1993;69:415-20.

16 Mayaud P, Grosskurth H, Changalucha J, et al. Risk assessment and other screening options for gonorrhoea and chlamydial infections in women attending rural Tanzanian antenatal clinics. Bull World Health Organ 1995;73:621-30.

17 West B, Changalucha J, Grosskurth $\mathrm{H}$, et al. Antimicrobial susceptibility, auxotype and plasmid content of Neisseria gonorrhoeae in northern Tanzania: emergence of high level plasmid mediated tetracycline resistance. Genitourin Med 1995;71:9-12.

18 Wellington $M$. Detection of asymptomatic carriers and partner notification. In: Prevention and management of sexually transmitted diseases in Eastern and Southern Africa: current approaches and future directions. Nairobi: Naresa current approaches and future directions. Nairo
Monograph No 3, Naresa, PO 11771, 1994.

19 Cowan F. The role and effectiveness of partner notification in STD control: a review. Genitourin Med 1996;72:247-52.

20 Harrison A, Wilkinson D, Lurie M, et al. Improving quality of sexually transmitted disease case management in rural South Africa. AIDS 1998;12:2329-35. 